\title{
KEY ASPECTSOF THE PROBLEMS OF ADMINISTRATIVE CONTROL IN BULGARIA
}

\author{
Venelin Terziev ${ }^{1 *}$, Nikolay Nichev ${ }^{2}$, Evgeniy Stoyanov ${ }^{3}$, Marin Georgiev ${ }^{4}$ \\ ${ }^{1}$ Corresponding Member of the Russian Academy of Natural History, Moscow, Russia, Professor, \\ Ph.D., D.Sc. (National Security), D.Sc. (Ec.), University of Rousse, Rousse, Bulgaria; National \\ Military University, Veliko Tarnovo, Bulgaria; University of Telecommunications and Post, Sofia, \\ Bulgaria, terziev@skmat.com \\ ${ }^{2}$ Colonel Associate Professor, Ph.D., National Military University, Veliko Tarnovo, Bulgaria, \\ nicheff@gmail.com \\ ${ }^{3}$ Professor, Ph.D., D.Sc. (Ec.), Agricultural University, Plovdiv, Bulgaria, evg_stojanov@abv.bg \\ ${ }^{4}$ National Military University, Veliko Tarnovo, Bulgaria, clementon@abv.bg \\ ${ }^{*}$ Corresponding author
}

\begin{abstract}
This article addresses the processes in the state related to regulation, organization and control, which essentially form the object of administrative control. The purpose of this analysis is to reveal the growing problems and their sources. As the executive authority is distinguished among them, the local selfgovernment, the prosecutor's office, and the justice system have a specific character because each designated source acquires the features of an object in the control systems appropriately separated from the state. The idea of the expose is to present another point of view, revealing some features of the objects in question, so that the system of general and administrative control can look for solutions to the weaknesses identified in the functioning of the specific systems in particular and, more generally, in its work by extending the scope of powers delegated by it or exercised by itself.
\end{abstract}

Keywords: state, control, power, justice, prosecution.

\section{MAIN TEXT}

The theoretical elucidation of any problem occurred is related to analysis, identification of alternatives and solution finding. But when the problems become more and the analysis of the causes and the search for principle solutions is multidirectional, the whole process becomes complicated and multi-layered and unfortunately does not always generate the expected results. All this supports the understanding of philosophers, consultants, and critics that progress has a complex and contradictory nature, cause, and functional meaning (Kanev, 2013, p. 20).

Whether as J. Schumpeter defines the main trend, revealed in the analysis of the present article as creative destruction is not so essential, the main and leading point is that progress in modern society is based on the 
conduct of scientific, technological, information-communication and socio-economic changes. This trend has become a major factor in rethinking social experience and established traditions (Stoyanov, 2014, p. 8). This is the reason to find that experience and traditions acquire a new, different meaning. This confirms the view that reality adheres to an established canonical form, at the same time revealing the dynamics of its perfection (Terziev, Arabska, 2016a).

Under these conditions and circumstances, the society as well as its specific elements or entities are subject to change. In the process of communication and interest, the patterns of behaviour used are becoming more and more unpredictable and diverse (Stoyanov, 2016, p. 102). It is for this reason that the challenges to all manifestations of control at all levels of society and among all social strata are becoming more and more difficult and delicate.

Although control over recent years has been growing steadily, and in terms of its theoretical development and its formal institutional improvement, the expectations and needs of the society towards and from it are becoming more and more important (Terziev, Arabska, 2016b, p. 690). In this context, the place and role of the state as a leading controlling entity and a supreme institutionalizing and institutionally represented organization are becoming even more serious. However, in order to reveal a small part of the problems of the administrative control, several clarifications should be made, arising from the retrospective and comparative legal analysis of control:

First. In its long history, control proves that it is differentiated on the basis of a critical public attitude towards the person's behaviour or an organized, personal formation that has arisen in the creation of goods.

Second. In the process of its improvement, management asserts the place of control as a compulsory last step in its structure. It is precisely that control as a corrective mechanism, comparing a fixed norm with registered results purposefully, makes the necessary changes.

Third. Different circumstances and situations provoke the emergence of a number of formal manifestations of control wherein different control systems different level control subjects are established. In them, the exercise of control is predetermined by the access to power resources on the basis of which the delegated control-managerial powers are properly and lawfully exercised.

Fourth. The presence of the state in the implementation of the control and governance processes guarantees presence of statehood, institutionalization and application of law. These are factors that imply the purpose differentiation of the different types of power - legislative, judicial and executive.

Fifth. In accordance with its place and role in the development of society and its social hierarchy, the different types of organizational structures, according to their essential characteristic and nature of work, exercise different types of control influence, revealing features both of control and supervision. In this context, although the sovereign is one, there is an opinion that control predominantly is an important power of the executive authority, and supervision according to the same logic - of the judiciary. (Balabanova, 2004, p. 19) Another position opposes this claim by justifying the existence of a huge power resource allocated to the executive. Maybe in principle, the solution that the society expects is not how it will be called the applied corrective mechanism, but what results it generates, how it justifies the expectations and protects its interests.

The briefly discussed views on the development of the control idea create the conditions to address some specifics in the work of the important controlling entities and to reveal a small part of the concomitant problems. The critical review of the institutions is deliberately presented in a downward direction with the aim, after analysing the inherent problems in their work, to seek a connection between them in terms of inter institutional communication.

The highest-ranking entity exercising control in the Bulgarian state is the National Assembly. On the basis of the current Constitution and Rules of Organization of the activity of the National Assembly, the National Assembly, together with its legislative function, exercises its control function (The Constitution of the Republic of Bulgaria, prom. State Gazette No. 56/1991 with last amendment, Rules for Organization of the activity of the National Assembly, State Gazette, issue 44/1997). It is essential to know that the exercise of parliamentary control has significant legal implications. The main object of its work is the lawfulness and correctness of the actions of the administration. Disadvantages or problems in the work of the National Assembly in the course of control are developed in a content, formal and administrative aspect.

In principle and content, the first weakness is the measures of effect on the acts and on persons acting as central bodies of the executive authority. In the influence measures taken against individuals, the control efficiency is higher because, based on a vote of no confidence or resignation, individuals can be removed from the central executive authority. On the question of the acts of the central executive authority, the 
decision is complicated and difficult because, as in accordance with the law on normative acts, an act is subject to annulment only by the same act. (Law on the Normative Acts, State Gazette, 65/1995 with the last amendment).

Formally, parliamentary control has a variety of forms, such as: transformation, establishing and closure of ministries, no confidence vote (trust), resignations, etc. Here the problem does not arise from the implementation of the specific, formal event, but from the possible consequences and their relation with the balance between the various politically coloured interests.

Regarding the administrative basic principle set out in the Rules of the National Assembly, the possible control, although it is a permanent presumption, can only be implemented on Friday (the day of parliamentary control). By adding procedures, deadlines and other conditions set out in the same rules on the one hand, and on the other, the need to prepare the interviewed persons becomes difficult. By delaying the time to find an answer and a decision, it is in fact proven that control and its presence are meaningless due to the impossibility of introducing corrections or changes in registered socially significant deviations (Stoyanov, 2016, p. 99). And interpretations of the facts may be divergent, but always in such situations, any loss of time produces a deleterious effect (Simeonov, 1997, p. 6).

At a lower level in the social and governance hierarchy, local government authorities are subject to control. The relationship between them and the state authority is implemented by the district governor. (Law on Local Elections, State Gazette No 66/1995 and last amendment) Its powers are to suspend unlawful acts of municipal councils or to repeal illegal acts of mayors of municipalities (Law on Local Self-Government and Local Administration, SG, issue 77/1991). Although control in local self-government is regulated to run on two levels - between the bodies of the local self-government and by the district governor, problems still exist. (Law on Administration,SG. No.130/1998 with the last amendment).

In social and business society, it is believed that the control deficit can be interpreted as a result of the dynamically changing socio-political risk. In other words, the partial "disempowerment" of the district administration is compensated by the increase in the influence of certain persons leading specific "attractive" municipalities. In addition, taking into account the conceptually and politically diverse municipal councils and the difficult achievement of consensual solutions, then interaction becomes an unrealistic goal, and the possibility of a constructive dialogue that embraces the constructive critique - the chimera.

A significant and important participant in the process of development of the control over the work of the executive authority is also the Bulgarian Public Prosecutor's Office. Among the powers of authority assigned to it in the central position is the supervision of the observance of lawfulness in the acts and actions of the bodies of the executive authority (Law on the Judiciary authority, SG. No.59/1994). An expression of the authority powers of the prosecution in the exercise of supervision is the filing of a protest. This procedural act is invoked when the breach in government is the result of an unlawful act.

Although the activity of the prosecutor's office is related to the exercise of supervision in many spheres of public life, and it being a higher state institution it can self-summon itself, some authors argue that certain undefined regulative positions pose problems (Lazarov, 1971, p. 50). Specifically, as such, it may be pointed out that although the prosecution is, in essence, entitled to make suggestions to all public administration bodies regarding violations, illegal actions and their causes, the initiative is not provided for and regulated in the normative framework. This statutory omission at this stage creates an insurmountable barrier to the participation of the prosecution in building real prevention.

The last subject, placed in the focus of attention of the expose, is the Bulgarian court, which only implements justice on the territory of the state. An insignificant part of the work of the judiciary system is related to challenging administrative acts. The connection between the work of the administrative and control system and the judicial system is the opportunity to examine from a different angle the presence of legality in acts and actions of the state administrative apparatus. A number of specialists believe that the so-called ,judicial” control over acts and actions of the administration is not effective enough (Balabanova, 2004, p.110). The results are improved with the active involvement of internal administrative controls (Stoyanov, 2013, p. 166).

The problems that accompany the work of judicial control derive from some of its peculiarities:

First. It only affects the legal aspect of administrative activity, although the deficiency of legality always causes damage and losses (Atanasov, 1968, p. 29).

Second. It begins to function once the illegal action has ended, i.e. when there is a detrimental effect (Dinev, 1985).

Third. The court is deprived of initiative, that is, it does not have the opportunity to self-summon. 
The content of the report provides evidence to conclude that the problems that accompany the Bulgarian administrative control have a very diverse and serious nature. Finding solutions to them is a challenge facing academics and lawmakers. However, the possibility of ignoring the impact of these problems should not be postponed in time and thus to cause further damage, but should be thought of as a set of problems of the whole society. If the statesmen begin to think as owners, governors - as managers and the rulers - as part of society itself, maybe there will be found the will to change and to find solutions in both the specific spheres and in the entire society as well.

\section{REFERENCES LIST}

Atanasov A., (1968) Control of Economic and Budget Activity, S.

Stoyanov E.N., (2014) Small Business - Organization, Analysis and Evaluation, Libra Scorpio, B

Stoyanov E.N., (2016) Theoretical Foundations of Management, Libra Scorpio, B.

Stoyanov E.N., (2013) Audit - Sources and Institutionalization, Flat, Burgas.

Balabanova Hr., (2004) Administrative control, VFU, Varna.

Lazarov K., (1971) Indirect Control on the Lawfulness of Administrative acts in the Civil Procedure, Legal Thought No. 1.

Dinev M., (1985) Social Control and the Work Team, Profizdat, S.

Kanev M., (2013) The Concept of Progress Beyond Economics, East-West, S.

Simeonov O., (1997) Theoretical Control Issues, Akadem Consult, S.

Terziev V., E. Arabska, (2016a) Innovation in Public Policies of Bulgaria, Yearbook of Shumen University K. Preslavski.

Terziev V., E. Arabska, (2016b) Implementation of Active Labor Market Policies in Bulgaria, Collection, vol. 7 from the Annual Conference of the NBU.

The Constitution of the Republic of Bulgaria, prom. State Gazette No.56/1991 with last amendment.

Rules for Organization of the activity of the National Assembly, State Gazette, issue 44/1997.

Law on the Normative Acts, State Gazette, 65/1995 with the last amendment.

Law on Local Elections, State Gazette No. 66/1995 and last amendment.

Law on Local Self-Government and Local Administration, SG, issue 77/1991.

Law on Administration,SG. No.130/1998 with the last amendment.

Law on the Judiciary authority, SG. No. 59/1994. 